\title{
Plano para o Lançamento de um Concurso Europeu na Área das Humanidades:a Idade Latina como Fonte de Respostas às Interrogações Prementes da Atualidade
}

\author{
Robert Martins Junqueira ${ }^{1}$ \\ ${ }^{1}$ Affiliation not available
}

May 7, 2021

Este exercício foi elaborado por Robert Junqueira no âmbito da Unidade Curricular de Negociação, Avaliação e Elaboração de Candidaturas da Pós-Graduação em Gestão e Políticas de Ciência e Tecnologia da Faculdade de Ciências Sociais e Humanas da Universidade NOVA de Lisboa, ministrada por Filipa Borrego, João Cortez e Margarida Trindade.

1: Âmbito Temático

2: Propósito

3: Elegibilidade

3.1: Candidata/os

3.2: Propostas

4: Financiamento

5: Processos

5.1: Candidatura

5.2: Avaliação

6: Recurso

7: Bibliografia

A fim de estimular a qualidade e o impacto dos projetos de investigação sobre a Idade Latina na área das Humanidades, a Agência Executiva do Conselho Europeu de Investigação (CEI) irá proceder ao lançamento do «Concurso Europeu na Área das Humanidades: a Idade Latina como Fonte de Respostas às Interrogações Prementes da Atualidade».

\section{1: Âmbito Temático}

Por Idade Latina entende-se, aqui, o período da história das ciências e culturas na Europa compreendido entre 354, o final da Idade Antiga, de expressão predominantemente grega, e 1644, a ascensão da Idade Moderna, de expressão multilinguística e inovador critério de cientificidade (cf. Deely 2001, 2010 e 2020). A datação é apresentada de forma tão precisa porque carrega um caráter simbólico, apresentando como ponto de partida o nascimento de Agostinho de Hipona e como fronteira última o ano de publicação dos Princípios de Filosofia de René Descartes e a morte de João de São Tomás. A Idade em que se originaram as chamadas Artes Liberaiso quadrívio da aritmética, geometria, astronomia e música mais trívio da gramática, dialética e retórica, formando o cânone educativo que recebeu, no coração da Idade Latina e muito graças a Hugo de São Vítor, 
também as ditas Artes Técnicas, como sejam a carpintaria e a agricultura (cf. Lagerlund 2019, 36) - tem sido relegada para a escuridão que naturalmente se reserva a uma extensão temporal que se tem depreciado com o título de Idade das Trevas. A busca pelo controlo e por possibilidades de exploração desmesurada de recursos naturais e humanos por parte da própria humanidade, que se acentuaram na Idade Moderna com a evolução da técnica e o estabelecimento, desenvolvimento e instrumentalização de doutrinas científicas baseadas na experimentação, desembocou nos séculos XX e XXI numa realidade que apresenta dois rostos que destoam: por um lado, herdámos um mundo infestado de necessidades às quais urge acudir; por outro, foi-nos legada a competência científico-técnica para que a resposta às urgências do agora seja sustentada em conhecimentos consistentes e aprofundados. Contudo, os excessos da secularização moderna - seguramente alimentados mas nunca justificados pelos da Inquisição - levaram quase ao oblívio completo do legado proveniente de várias geografias ao longo de um período de tempo que abarca cerca de 1290 anos, Idade em que para além de abusos e erros foi também forjado um quadro intelectual que visa justificar a coexistência pacífica de esferas relativas - como sejam diferentes personalidades, povos e culturas ou também a fé e a razão-, tal como o quão desacertado é proceder à interpretação das diferentes esferas sem reconhecer-lhes uma autonomia hermenêutica relativa (para uma interessante leitura sobre este tema e sobre o papel central desempenhado pela tradição arábico-islâmica veja-se Deely 2001, 186-193 e Carvalho 2020, 10; 37). Importa, ainda, notar que não é apenas no âmbito das relações entre personalidades, povos e culturas que poderá a recuperação da Idade Latina ser valiosa: também para o pensamento que no presente é dedicado à relação entre a humanidade e o meio ambiente poderemos encontrar na Idade Latina uma interlocução à altura: na Idade Latina, lembrou Deely (2001, 72), já se reconhecia que não existem indivíduos senão em relação com o seu ambiente, este que é elemento incontornável no próprio ser de cada qual.

\section{2: Propósito}

Este programa visa financiar projetos centrados em temas, tradições e autora/es da Idade Latina, por forma a colocá-los diante dos desafios da contemporaneidade. Os projetos devem buscar contribuir para que os Objetivos de Desenvolvimento Sustentável (ODS) da Organização das Nações Unidas (ONU) sejam melhor compreendidos, transmitidos e alcançados. Os projetos deverão, preferencialmente, abordar questões sobre a forma como que a herança da Idade Latina nos pode ajudar a erradicar ou a pensar a erradicação da pobreza e da fome, garantir ou pensar a saúde e educação de qualidade, igualdade de género, a ecologia, a dignidade humana, as desigualdades, as cidades, a sustentabilidade, o valor da vida, a paz, a justiça e o lugar das instituições. Assim, as Humanidades serão estimuladas a contribuir para que seja dada uma resposta às interrogações mais prementes da atualidade. Para além disso, a mobilidade de investigadora/es em princípio de carreira na área das Humanidades será estimulada no seio da UE. Prevê-se que este concurso fomente a reabilitação de importantes momentos de uma época suprimida do conhecimento comum, dissipada pelo passado fora e abafada ao longo da Idade Moderna. A finalidade principal deste concurso consiste, portanto, em financiar um conjunto notável de investigadore/as talentosa/os empenhados na divulgação da vasta densidade da Idade Latina enquanto inexaurível fonte de orientação para fazer face, com um olhar voltado para o porvir, às inquietações da contemporaneidade.

\section{3: Elegibilidade}

\section{1: Candidata/os}

Apesar deste concurso ser designado de "Concurso Europeu", apenas candidata/os nacionais dos 27 Estadosmembros independentes da União Europeia poderão concorrer. No âmbito das candidaturas individuais será dada preferência a jovens investigadora/es talentosa/os em princípio de carreira que tenham concluído o Doutoramento no máximo há 3 anos, se bem que serão elegíveis toda/os a/os candidata/os que tenham concluído o Doutoramento há menos de 10 anos, i.e., no ano fiscal de 2011. A preferência dada a jovens investigadora/es talentosa/os em princípio de carreira que tenham concluído o Doutoramento no máximo há 3 anos materializa-se na limitação de 7 pacotes de financiamento individual a projetos apresentados por candidata/os que apresentem esse perfil. Serão elegíveis toda/os a/os candidata/os independentemente da sua proveniência e género, mas será estimulada a equidade e a interação, por via da atribuição de 7 pacotes de financiamento exclusivamente voltados para projetos mistos. Estes projetos devem ser mistos na medida 
em que as candidaturas devem ser apresentadas conjuntamente por uma investigadora e um investigador com diferentes nacionalidades e proveniências institucionais distintas.

\section{2: Propostas}

Os projetos devem enquadrar-se em alguma das áreas das humanidades ou nos seus cruzamentos. Será dada preferência a projetos que incluam ou se insiram no desenvolvimento de investigação sobre o período tardio da Idade Latina nas áreas da filosofia, da geografia, da história e da linguística, tal como a projetos que se debrucem sobre a contribuição de filósofas de qualquer proveniência, etnia, credo e cultura tal como da filosofia arábico-islâmico para a atualidade e o diálogo científico e cultural na Idade Latina. Os pacotes de financiamento são concedidos numa perspectiva do topo para a base, pois os projetos devem procurar contribuir para que os ODS da ONU sejam melhor compreendidos, transmitidos e alcançados. Serão imediatamente rejeitadas todas as propostas que não declarem expressamente a relação entre a investigação a desenvolver e os ODS da ONU. Os projetos individuais devem prever duas fases de desenvolvimento a serem levadas a cabo em duas instituições sediadas em países distintos daquele do qual a/o candidata/o provém. As candidaturas aos pacotes de financiamento para projetos mistos devem ser apresentadas por uma candidata e um candidato que pretendam levar a cabo, em conjunto, um projeto de investigação em duas fases, em instituições sediadas em dois países diferentes daqueles de onde a candidata e o candidato são provenientes. Todas as instituições envolvidas (de proveniência e de destino) devem estar sediadas num dos 27 Estados-membros da União Europeia (UE), podendo ser instituições de investigação públicas ou privadas. A duração dos projetos deverá ser superior a 32 meses e inferior a 37 meses, e deverão ter início dois meses após a publicação dos resultados da avaliação.

\section{4: Financiamento}

Prevê-se a atribuição de um total de 5.100.000, distribuído em 27 pacotes de financiamento: 20 para candidaturas individuais (150.000 para cada projeto financiado) e 7 para candidaturas mistas (300.000 para cada projeto financiado). Caso não haja 7 candidaturas mistas acompanhadas de uma avaliação positiva, cada um dos pacotes de financiamento remanescentes será repartido em 2 pacotes de financiamento para projectos individuais e cada um dos pacotes de financiamento resultantes será atribuído a outros projectos individuais qualificados com uma avaliação positiva. Os pacotes de financiamento serão concedidos a/os investigadora/es diretamente mas de forma faseada, sendo o total do financiamento a atribuir dividido pelo número de meses da duração do projeto. No caso dos projetos mistos, o pacote de financiamento será concedido ao par mas adjudicado separadamente, pelo que cada participante do projeto receberá o valor correspondente ao de um pacote de financiamento para projetos individuais. Cada investigador/a poderá beneficiar de um financiamento suplementar de 1500/ano para estadias e deslocações para qualquer país do mundo. A atribuição do subsídio para deslocações/estadia será feita na forma de reembolso e exigirá que o/a investigador/a apresente um requerimento para o efeito, acompanhado de uma justificação, a apresentar ao CEI nos meses de janeiro ou fevereiro do ano fiscal imediatamente a seguir ao da contração das despesas. Caso o painel de avaliação da CEI considere que a fundamentação carece de sentido, o requerimento será indeferido, sem possibilidade de recorrer da decisão do painel.

\section{5: Processos}

\section{1: Candidatura}

Esta é a primeira edição do Concurso Europeu na Área das Humanidades: a Idade Latina como Fonte de Respostas às Interrogações Prementes da Atualidade, que decorrerá anualmente por tempo indefinido. Para que a candidatura seja validamente lacrada, os formulários oficiais, o projeto de investigação e os documentos suplementares, que incluem a carta de aceitação das instituições-destino, a carta de motivação e todos os documentos pessoais listados no regulamento, deverão ser incluídos. A candidatura deverá ser lacrada até ao dia 31 de agosto, e os resultados serão publicados a 31 de outubro (validação das candidaturas) e 31 de dezembro (avaliação das candidaturas). As chamadas foram publicadas nesta página, na página do CCI, no portal de Financiamento e Concursos da Comissão Europeia e enviadas por via eletrónica para todas as Unidades de I\&D na área das Humanidades sediadas na UE. Candidata/os deverão ler a 
chamada atentamente e redigir uma proposta original. Não serão aceites projetos que se limitem a propôr um aprofundamento de temas já antes tratados por si ou por outrem, a não ser que o façam em resposta ao ODS número 4, procurando não só ir mais fundo na investigação mas também tornar os seus resultados acessíveis gratuitamente numa plataforma em linha num formato adequado para que constituam uma oferta de aprendizagem ao longo da vida ou voltada para crianças com menos de 12 anos de idade. Recomenda-se que a/os candidata/os se familiarizem atempadamente com o serviço para a submissão de propostas da UE e submetam as suas propostas tão cedo quanto lhes seja possível. Assim que o fizerem, será enviado um email para o endereço facultado no formulário com o documento unificado da candidatura que será apreciado pelo painel de avaliação, incluindo os anexos. Nenhuma proposta poderá ser apresentada ou alterada uma vez ultrapassada a data-limite; antes disso, as propostas submetidas poderão ser alteradas um número ilimitado de vezes por via do upload de um novo documento na secção "Projeto", o que levará à substituição do anterior documento pelo novo e ao envio de um novo email com o novo documento unificado da candidatura. No fim da fase de validação das candidaturas, o CEI informará toda/os a/os candidata/os sobre a validação ou não-validação das suas propostas, que poderão ou não avançar para a fase de avaliação das candidaturas por parte de um painel de especialistas externos ao CEI, recrutada/os por este. Apenas propostas validadas seguirão para o processo de avaliação por um painel de especialistas externos.

\section{2: Avaliação}

As propostas serão avaliadas por um painel internacional de especialistas externos ao CEI com base na excelência e na sua articulação com os ODS da ONU. O painel de avaliação irá apreciar e avaliar todas as propostas que passem da fase de validação de candidaturas. Na presente edição deste concurso, o orçamento e as tipologias dos pacotes de financiamento não sofrerão alterações, podendo ser alvo de aumento, decréscimo ou revisões em edições posteriores. A execução dos pacotes de financiamento fica-se pela atribuição dos mesmos, mas a não-execução dos projetos ou de parte destes levará à instauração de um processo visando a averiguação das causas. Em casos de não-execução parcial ou total dos projetos, poderá ser exigida ser exigida a devolução total ou parcial do financiamento por parte da/os candidata/os. O painel de avaliação será constituído por 54 membros, uma investigadora e um investigador especializada/os em temas da Idade Latina e provenientes de cada Estado-membro da UE, que serão selecionada/os pelo Conselho Científico da CEI com base na sua reputação científica. Os nomes dos membros do painel de avaliação serão tornados públicos na página Web da CEI apenas na data em que tenha sido dada resposta a todos os eventuais recursos.

\section{6: Recurso}

A/Os candidata/os dispõem da prerrogativa de interpor recurso perante as decisões tomadas pelo painel de avaliação nos casos do indeferimento imediato das propostas e na sequência dos resultados da avaliação. Para recorrer da decisão do painel de avaliação na fase de validação das candidaturas, a/os candidata/os deverão fazê-lo até 10 dias depois da publicação dos resultados, e receberão a resposta no decorrer dos 15 dias seguintes à interposição do recurso. O recurso na sequência dos resultados da avaliação deverão ser apresentados até 15 dias após a publicação dos resultados, e serão informados do resultado da apreciação do recurso no decorrer dos 20 dias após a interposição do mesmo. Todos os recursos serão apreciados por um painel de avaliação externo recrutado para o efeito pelo Centro Comum de Investigação (CCI). Por cada recurso, será enviado um despacho escrito para o CEI e para a/os candidata/os que apresentaram o respectivo recurso, a especificar e fundamentar a decisão, favorável ou não, do CCI. O CCI pode:

i) considerar o recurso desprovido de mérito e sustentar a anterior decisão da CEI;

ii) constatar que apenas erros irrelevantes ou inofensivos foram detectados no processo de atribuição de financiamento da CEI e, como tal, indeferir o recurso;

iii) considerar o recurso meritório e poderá

iii.i) proceder à inclusão da candidatura original, conforme apresentada, no processo de apreciação e avaliação da candidatura, sempre que esta tenha sido indeferida de imediato, o que não assegura a concessão do 
financiamento, antes permitindo que a proposta inicialmente indeferida seja novamente inscrita no processo de avaliação para efeitos de atribuição de financiamento;

iii.ii) ou estipular as medidas necessárias, que poderão compreender, designadamente, a atribuição parcial dos fundos, uma nova avaliação das candidaturas ou quaisquer outras medidas previstas pelo CEI e pelo CCI para os casos de recursos meritórios apresentados posteriormente à publicação dos resultados da avaliação.

\section{7: Bibliografia}

Esta bibliografia não é uma lista de obras para a/os candidata/os do concurso, mas tão só a breve lista de obras que referi neste trabalho.

Carvalho, Mário Santiago de. Falsafa. Breve introdução à filosofia arábico-islâmica. 2.a ed. eQuodlibet. Coimbra: Instituto de Estudos Filosóficos, 2020. https://doi.org/10.5281/zenodo.4420368.

Deely, John. Four ages of understanding: the first postmodern survey of philosophy from ancient times to the turn of the twenty-first century. Toronto studies in semiotics. Toronto e Buffalo: University of Toronto Press, 2001. https://doi.org/10.3138/9781442675032.

- Medieval Philosophy Redefined as the Latin Age. 1st edition. South Bend, Indiana: St. Augustines Press, 2020. https://www. staugustine.net/our-books/books/medieval-philosophy-redefinedas-the-latin-age/.

- Medieval Philosophy Redefined: The Development of Cenoscopic Science, AD354 to 1644 (From the Birth of Augustine to the Death of Poinsot). Scranton, PA: University of Scranton Press, 2010. https: //press .uchicago.edu/ucp/books/book/distributed/M/bo10192605.html.

Lagerlund, Henrik, ed. Knowledge in Medieval Philosophy. The Philosophy of Knowledge: A History. London, New York, Oxford, New Delhi e Sydney: Bloomsbury Academic, 2019. http://dx.doi.org/10.5040/ 9781474258340. 